\title{
Fargo: seeing the significance of style in television poetics?
}

Article

Accepted Version

Sexton, M. and Lees, D. (2019) Fargo: seeing the significance of style in television poetics? Critical Studies in Television: The International Journal of Television Studies, 14 (3). pp. 343361. ISSN 1749-6020 doi: https://doi.org/10.1177/1749602019853792 Available at https://centaur.reading.ac.uk/100689/

It is advisable to refer to the publisher's version if you intend to cite from the work. See Guidance on citing.

Published version at: https://journals.sagepub.com/doi/10.1177/1749602019853792

To link to this article DOI: http://dx.doi.org/10.1177/1749602019853792

Publisher: Sage

All outputs in CentAUR are protected by Intellectual Property Rights law, including copyright law. Copyright and IPR is retained by the creators or other copyright holders. Terms and conditions for use of this material are defined in the End User Agreement.

\section{www.reading.ac.uk/centaur}

\section{CentAUR}

Central Archive at the University of Reading 
Reading's research outputs online 


\title{
Fargo: Seeing the significance of style in television poetics?
}

By Max Sexton and Dominic Lees

6 Keywords: Poetics; Mini-series; Style; Storyworld; Coen brothers; Noah Hawley

\begin{abstract}
This article argues that Fargo as an example of contemporary US television serial drama renews the debate about the links between Televisuality and narrative. In this way, it seeks to demonstrate how visual and audio strategies de-stabilise subjectivities in the show. By indicating the viewing strategies required by Fargo, it is possible to offer a detailed reading of high-end drama as a means of understanding how every fragment of visual detail can be organised into a 'grand' aesthetic. Using examples, the article demonstrates how the construction of meaning relies on the formally playful use of tone and texture, which form the locus of engagement, as well as aesthetic value within
\end{abstract} Fargo.

At the same time, Televisuality can be more easily explained and understood as a strategy by writers, directors and producers to construct discourses around increased thematic uncertainty that invites audience interpretation at key moments. In Fargo, such moments will be shown to be a manifestation not only of the industrial strategy of any particular network - its branding - but how is it part of a programme's formal design. In this way, it is hoped that a system of television poetics - including elements of camera and performance - generates new insight into the construction of individual texts. By addressing television style as significant, it avoids the need to refer to pre-existing but delimiting categories of high-end television drama as examples of small screen art cinema, the megamovie and so on.

\section{Main Article}

\section{Television poetics and narrative expansion}

Television's operation invites comparisons with cinema due to its recent technological changes and the desire to be cinematic for certain types of prestigious drama that rival film in its quality and complexity. ${ }^{\mathrm{i}}$ In many ways, the recent 'film look' in US television drama from Netflix, Amazon, HBO, and others is a moniker based on high 
production values and feature cinematography. ${ }^{\text {ii }}$ However, the value, scope and meaning of change within television drama in the previous decades ought to be considered as much in a cultural context as an economic or technical one. High-end television's own distinctive forms suggest less notions of worth about types of drama that are predicated on technical quality - the choice of camera and so on - than its cultural significance as a storytelling medium to reflect further on our perception of events and the nature of the television text.

Fargo the television series premiered in 2014 on the FX channel and consists of separate stories for its three seasons that consist of ten episodes using new characters. ${ }^{\mathrm{iii}}$ Structurally and formally, Fargo depends on developments as the event concept for TV drama has evolved and, enabled by increased budgets, seriality, and production values on television, drama has become a key marker of quality in prime time programming. ${ }^{\text {iv }}$ Unlike the film business, the television production of drama has historically worked with smaller budgets and this has been expressed as a willingness to take chances on new material. For example, according to Nik Grad, FX’s president of original programming: 'It’s a smaller bet. You're not talking about a \$100 million negative. There is the relationship between what things cost and how much leeway and elbow room you get.'v More recently, this has matched the money spent on mid-range theatrical films. For example, the budget for the original Fargo film was $\$ 7$ million but the pilot episode of the first season of the TV series cost \$3 million with subsequent spending on the remaining episodes. Other examples include the \$20 million spent on the pilot episode of Boardwalk Empire (2010). Other production values continue to be imported into the mini-series that capitalise on prestige-endowing theatrical talent, including Todd Haynes’ version of James M. Cain’s Mildred Pearce (2010) starring Kate Winslet. It was Winslet's first work since winning an Oscar for The Reader (2009) and with a budget of $\$ 20$ million for five episodes marked another further change in the status of television drama, specifically the mini-series. ${ }^{\mathrm{vi}}$

Many of these programmes were not originally available to see on television except on cable or else streamed on the internet using a subscription service. It is the search for brand enhancement due to competition among pay cable channels such as FX that has meant that the long form of storytelling has been evaluated as aesthetically and structurally superior within television for dramatic purposes. ${ }^{\text {vii }}$ However, as we will see, the notion of cultural and aesthetic status of the mini-series is complicated by the choice of subject beyond facts such as a programme’s budget. For example, Fargo's serial 
narrative allows greater depth and more complexity in the construction of character but, crucially, also succeeds in marrying visual style to the narrative concerns of the noir genre: crime, sex and betrayal, including themes such as deception and misunderstandings that result in ruin. Additionally, visual richness and narrative diversity within Fargo comes from the fact that the series works towards the critical exploration of its genre rather than using it as it is understood within existing production and viewing practices. ${ }^{\text {viii }}$ As we will also see, narrative ruminations in the show distinguish it as being 'quirky' which, as a further example of brand building for FX, is used to characterise its complexity and experimentation to produce a playfully textual mode within television drama.

While visual sophistication within television has been responsible for greater narrative scope the possibility of a grand aesthetic design in drama that flaunts or produces a self-conscious style is less sure. It should be recalled that structurally Fargo depends on the certainty created by the cohesive systems of production design and performance, as well as genre with its semantic and syntactic conventions, albeit amid increased uncertainty created by strategies of narrative complexity. Fargo rests upon the closeness of the macabre and the everyday, while maintaining stylistic restraint. If it invites audience interpretation at key moments, it balances narrative ruminations with an insistence on narrative closure within the mini-series. On the one hand, the stories in Fargo are a prelude to creating complex character genealogies that relate the characters together in unexpected ways. However, if formal restraint exists, de-stabilized subjectivities within the narrative are explored using its under-stated sensibility, as the entwined personal history of its main characters invite an interpretative engagement with the show.

A grand aesthetic design within a single drama can appear distracting when much of television production usually depends on assembly-line efficiencies. Yet, at the same time, aesthetic unity within a programme has acted as an acknowledgement of creativity and the ability of television drama to offer the viewer an artistic experience. By the 1990s, John Caldwell would isolate three types of televisual auteurs: the 'showcase producers’ offering 'marque signature [as] network banner carriers', 'mainstream conversion producers' who ‘acquired mannerisms [and] 'embellished genres' and 'auteur-imports' from the cinema who produced 'cinematic spectacle' and were regarded as 'visionary emigres'. ${ }^{\text {ix }}$ Underlying these alternative ways of thinking about the relationship between a programme and authorship is the possibility of how 
both personal idiosyncrasies but also interpretive consistency raises the same type of judgments about stylistics that feature film has attracted which link narrative and aesthetics.

\section{Developing the storyworld of Fargo}

Beyond subject and stylistic choices that rely on serial modes, Fargo's recent development can be regarded as an example of the need to create a self-sufficient world without the need for recourse to a primary text. Yet, at the same time, Fargo has a complex genealogy by possessing a memory of the original film released in 1996 and by referring back to its source. For example, in series one, Martin Freeman plays Lester Nygaard after William Macy had played Jerry Lundegaard, an insurance salesman similarly trapped in a loveless marriage. Next, there is Allison Tolman playing Molly Solverson, a pregnant police officer, after Frances McDormand had played the similarly pregnant Marge Gunderson. There is also Billy Bob Thornton playing Lorne Malvo, who approximates to Gaear Grimsrud played by Peter Stormare. However, Colin Hanks is a Duluth police officer and single parent in the TV show without an obvious counterpart to the characters in the film.

Although John Landgraf was reported to say that there would be no crossover, he would also claim that the series would be 'remarkably true to the film' with Joel and Ethan Coen taking executive producer credits. ${ }^{\mathrm{x}}$ The convergence between theatrical film and television drama -prefigured to some extent by the crossover between the TV movie and serial drama in earlier decades - was the first venture by the Coen brothers onto the small screen. ${ }^{\mathrm{xi}}$ However, despite their prestige as writer-directors of a highstatus primary text, their participation is complicated by their executive status and lack of direct involvement in the development of the series. In fact, their executive status should be understood not as evidence of involvement but part of the 'deal' that brought together a producer (Littlefield/Hawley), a writer (Hawley) and a star (Billy Bob Thornton) into conjunction with other executives (Landgraf).

Thornton had already been in two Coen brothers films: The Man Who Wasn't There (2001) and Intolerable Cruelty (2003) but Fargo was Thornton's entrée into cable television's edgier drama. It was Thornton's decision to play the part which encouraged others to sign to the production, including Tolman and Hanks. Thornton's casting demonstrates that if theatrical talent is a big draw for producers and programme buyers it signals another trend: those working in high-end television are behaving more like film 
producers. By casting Thornton, Littlefield and Hawley were pulling together the elements that would secure funding from the broadcaster, as well as screen agencies and rights distributors for FX. ${ }^{\text {xii }}$ Theatrical talent can also be drawn to the limited shooting time - just 12 weeks for the shooting of Fargo. ${ }^{\text {xii }}$ Like shooting a mid-range film, a limited shooting time anticipates losing the lead after the production. Unlike a show such as $X$-Files and the casting of David Duchovny and Gillian Anderson, Thornton was to star in one series but left to pursue new projects. ${ }^{\text {xiv }}$ In Fargo, the desirability of a storyworld made up of separate time-lines in subsequent series with new sets of characters is as much a practical determination as one concerned with advancing the show in terms of newer narrative possibilities.

Consequently, the contribution of the Coens was limited to recommending a casting director, Rachel Tenner, who had worked on the original film to assemble the show's cast. ${ }^{\mathrm{xv}}$ The absence of creative control by the Coens acts as a reminder of the importance of other players in developing Fargo the television show unlike, for example, the obvious cachet of Martin Scorsese directing the pilot episode of Boardwalk Empire (2010) or Todd Haynes as the showrunner for Mildred Pearce. Unlike Scorsese and Boardwalk Empire, the Coens would not establish the look of the show in the pilot episode.

The rights to the original 1996 film were first bought by Bruce Paltrow, who had previously produced Homicide: Life on the Streets (1993-1999) and St. Elsewhere (1982-1988). At NBC, a pilot script for Fargo by Paltrow was developed based on the main character from the feature film: Marge Gunderson. However, NBC decided not to use the script. Warren Littlefield, former NBC Entertainment President and later the executive producer of Fargo, remarks how the script was 'based on the character of Marge and the Fargo police department. It was good, but it had that network feel about it...Network television isn't ready to do this. ${ }^{\text {xvi }}$ Such a claim about the perceived problem with the script and the medium at a historical moment suggests not only a disparity between television drama and the feature film but an evaluation of network television. Richard Levinson, who helped to co-create many network series, including the Columbo series, makes the following points about network television: 'Networks are in business to deliver ratings. For them, numbers are almost a moral imperative. Network executives have no objection to quality - they prefer it - but it is far from their main priority.' xvii Such comments evoke the rhetoric of distinction, which is displayed 
as a commitment to production and script values but opposed to those in 'network television'.

In 1997, CBS made a pilot of the script, which was directed by Kathy Bates with Edie Falco starring in the Marge Gunderson role. Gunderson was still the pregnant police chief of Brainerd, Minnesota. Now she would begin a new case by investigating the murder of a town pharmacist by a stranger helping to jump his car battery. However, the TV movie was never broadcast. It was only later that Littlefield claims that he realised that television had sufficiently changed to make a television series of the film. However, if the industrial and technological infrastructures that had previously disqualified US network television drama from the status of art had been altered, what became the key to the new TV series would be its lack of fidelity to the original text. ${ }^{\text {xviii }}$ Rather than reference an older text as primary, the new series would include an additional time-line set in 2006 and not 1996 and become one story among many other stories, including the film. Littlefield approached MGM, at the time emerging from bankruptcy but which now held the rights, and the series was produced by FX, a cable channel owned by $20^{\text {th }}$ Century Fox.

The next key individual in the development of Fargo as an example of high-end TV drama is Noah Hawley, who ultimately became showrunner and writer of all ten episodes of the original series of Fargo. For Hawley, the show's inspiration was the last exchange in the film when Marge (Frances McDormand) tells the arrested killer, 'Here we are, and it's a beautiful day, and for what? A little bit of money.' Yet, Hawley wanted to tell separate, new stories each season rather than write either an anthology or a serial drama. Instead, in sub-created, parallel worlds, there would be a limited ensemble of characters that could dominate the action with a clear theme of growth and redemption from beginning to end. Importantly, there would also be a clear conclusion at the end of each season rather than an open narrative.

Historically, if the writer rather than the director is the creative artist within television drama, in the case of Fargo, in important aspects, it is not possible to identify the production with a single author. We have already seen that the development of Fargo extends earlier approaches about the nexus between institutional requirements and the psychological demands of the writer/ producer. Yet how far authorship in Fargo relies on or exceeds the limits of job demarcation and becomes the collaboration between its producers, directors, writers, actors depends not only on the individuals 
involved. It also relies on the regulated form of the mini-series that exists at the intersection of economics and technology, as well as television style.

For example, one perceived problem with older serial dramas such as $X$-Files and Lost had been the failure of the makers to determine a concluding point. ${ }^{\text {xix }}$ The novelist Stephen King believes that in the case of Lost '....stories should resemble life, and life has a beginning, a middle, and an end. ${ }^{\mathrm{xx}}$ Yet, the desire in Fargo to grow the main character of Molly Solverson and avoid the iteration King had observed in Lost does not suggest a refusal to counter the prospect of a digressive narrative. In the miniseries, Hawley would show a willingness to see the paths of the characters cross, diverge and re-cross if such structures were suborned to stories that included familiar dramatic pleasures about character growth, change and success. In these ways, for example, plot threads juxtapose around Solverson's romance with Hank’s character of Gus Grimly, as well as his finding redemption after showing moral cowardice as a policeman in episode one to establish key insights into the characters. An uncluttered but, at the same time, digressive pattern seeking equilibrium unfolds in Fargo as its episodic structure maintains thematic progression towards the narrative closure made possible by limiting the number of episodes per season.

One clue to the source of this approach to narrative can be observed in Hawley's earlier work. Noah had worked with his brother, Alexi, to write and produce a film called Dead in the Water. The film would be about zombies on a cruise ship and the script was later sold to Disney. According to an interview, Alexi was more interested in action beats, tension and scares, whereas Noah was more interested in character work and narrative arcs. ${ }^{\mathrm{xxi}}$ To reconcile these differing approaches to the script, both writers also wanted to work with concepts of nonlinear storytelling that would have multiple points of view and favour action-orientated stories while building suspense and the probing of the psychology of the characters. ${ }^{x x i i}$ The combination of beats and arcs can be found again in the narrative in Fargo, which is organised in a complex way: structured around flashback sequences and other narrative interpolations to create suspense and hermeneutic delay. However, at times, these features are designed to offer a more subjective and fragmented perspective within the visuals poetics in Fargo that almost becomes impressionistic at times.

Consequently, an analysis of style extends earlier approaches about the nexus between institutional requirements and the objectives of the director/ producer. Televisuality is not necessarily a personal style attributed to either the showrunner or 
institution but often demonstrates a complex and long production history embedded in Fargo, which the rest of this article seeks to explore.

\section{Fidelity and the significance of style}

In the case of Fargo, it is possible to claim that, in important aspects, it is not possible to identify the production with a single author because television production is a collective enterprise often requiring elaborate teamwork for a complex production such as drama. Moreover, a careful study of style in Fargo demonstrates how the television series deviates from an already established format, as well as raise questions about who is speaking within the text. As we will see, this complicates the sense of an autonomous individual capable of bringing a particular world-view as it has been applied to the cinema.

Using a series of irrational happenings, the transformation of Lester Nygaard, the hapless insurance salesman, creates for the viewer a profound emotional sense of a sensitive man overwhelmed by the snowy wilderness that eventually engulfs him. The transformation begins in episode one (The Crocodile's Dilemma) with Nygaard murdering his wife in the basement of their house after she berates him for his incapability as a man. This is presented in two ways. First, Nygaard hits his wife with a hammer followed by two plot twists that are close together to maximise the sense of a loss of control. Lester calls Malvo to help him dispose of the body but, in fact, he plots to shoot Malvo when he arrives and blame him for murdering his wife. This plot twist is immediately followed by a knock on the front door. Rather than Malvo, it is the Sheriff adding to the confusion.

Second, the complex transformation of the individual is presented by using what might be called a ‘taciturn' style that matches Nygaard's half-whispered expression as he commits violent murder. Earlier, his wife refers to his silence in bed and, hitherto, we have seen that Nygaard is shy and diffident, barely able to be heard among others. When he murders his wife, the sound is kept to a minimum. Similarly, the camera appears reluctant to approach the action establishing a stiff-lipped effectiveness that is used repeatedly in the series. The sequence is also handled less to evoke a feeling from the audience - shock, horror, fright - even if the shots themselves may, in fact, exude the quality of 'shock'. Rather, the style is used to present such qualities but the shots appear 'blind' to the narrative twists. This greater attention to the formally expressive qualities of the shot while resisting drawing the audience into the narrative at key 
moments is, as we will see again, a constant strategy used in Fargo. For the moment, there is little background noise or much camera movement that matches Lester's own spare use of dialogue. Nygaard's later status as a successful insurance man is signified by his excessive wordplay. The presenting of the shifting relations between antinomies between the ordinary and the extraordinary in Lester, as well as the other characters, reveals how complex meaning can be found within the style, which often exists as a series of hints that reward the viewer's attention to detail.

Another example of Fargo's restrained or taciturn style is in the sense of stillness of the snowy wastes both outdoors and indoors. Importantly, when the show uses scenes of snow in them to establish theme, the images often become non-focalised. In other words, the images are controlled by the narrator rather than controlled by any narrative agent within the show's diegesis. ${ }^{x x i i}$ For example, in episode one, when we watch Nygaard for the first time leave his home to walk to work there is a slow fade from a shot of his house to a second long shot taken from a high vantage point of his home town Bemidji. After a few seconds, to further establish setting, this is followed by another slow fade to a shot of a street with shops as a truck with exhaust steaming behind it drives by on the icy road. Next, a cut locates the spectator inside Nygaard's office, who is at his desk selling insurance to a young couple sitting opposite him. However, rather than the shot being fully contained within the diegesis, the camera is positioned behind Nygaard as it observes the setting of the other empty desks. Slowly, it tracks-in and we notice not one, two, but six globe paperweights on Nygaard's desk. The paperweights could have been an easily overlooked detail but a desk lamp is strategically placed to shine light on them. The paperweights are not directly involved in the unfolding action of the scene but using a change of camera angle appear incongruously at the bottom of the next two shots of the couple that Nygaard is talking to. At this moment, shot composition might yield extra abstract meaning about the milieu surrounding Nygaard. However, the use of production design, camera and editing also indicates the continued separation between spectator and the characters that we noticed earlier when Nygaard murders his wife. The short montage of Nygaard and Bemidji raises the possibility that the producers of Fargo may seek to render knowable the mysterious world of life in Minnesota using shots of the town and office. But the 
linking of the narrator with Hawley cannot always be sustained.

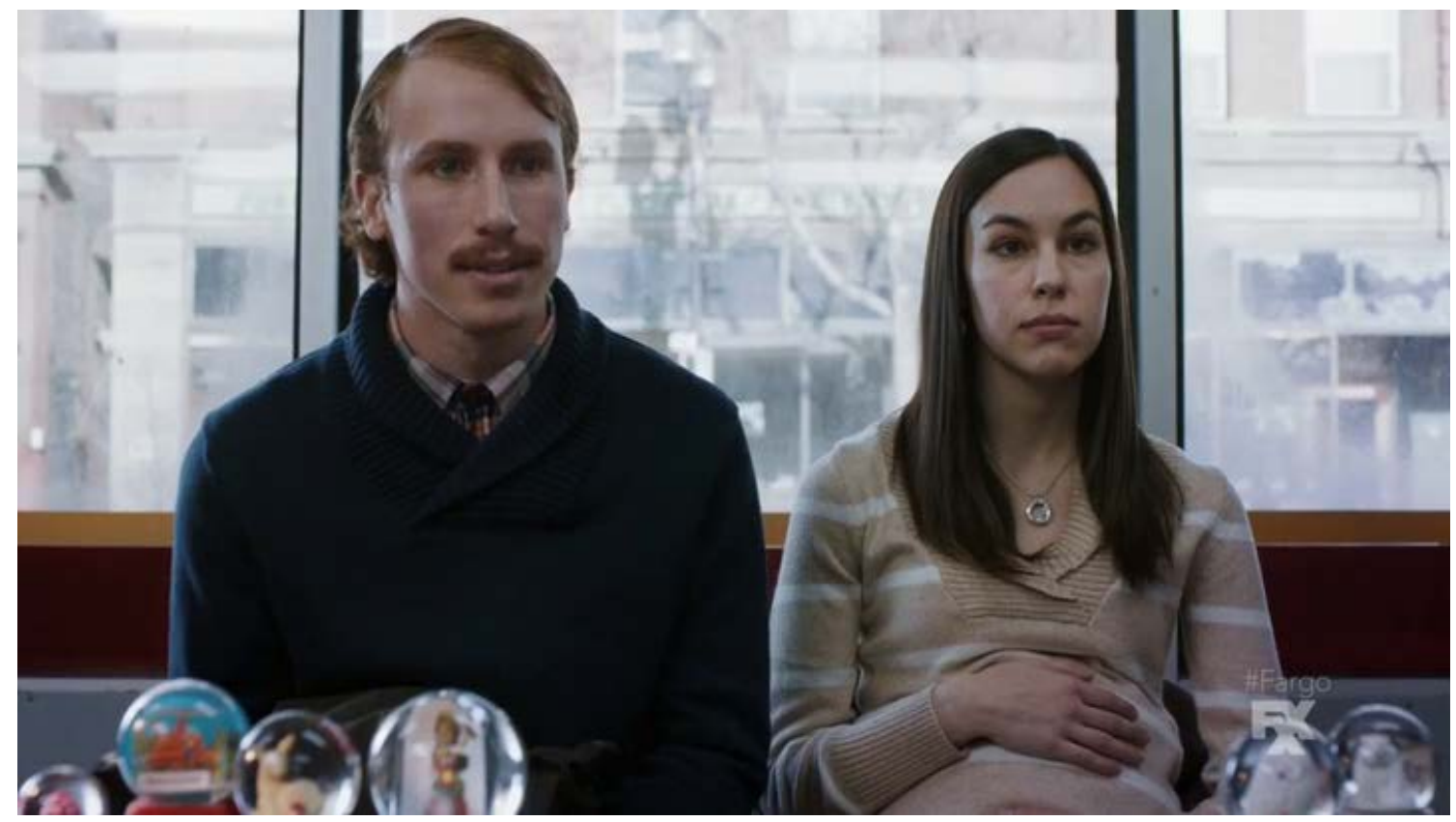

Crucially, the restrained style and use of odd detail is a form that suggests touristic travel journeying through the storyworld first created by the Coen brothers and adapted to television. In fact, the use of snow (outside and inside the paperweights) prefigures other visual cues throughout the series to elicit information about the nature of the storyworld and its 'quirkiness'. In this regard, the spectator's awareness and experience of the extended televisual narrative becomes Coenesque due to the heightened significance of particular props. At the same time, the separate shots of Bemidji are not simply transitional before we see Nygaard in his office. Rather, they are used to raise questions about the nature of the narration - who is talking here, the Coen brothers, Hawley, or the agency of the characters - to form a complex style in Fargo.

The nature of the narration is again raised when we are also asked to gaze upon the frozen features of the show's characters. This becomes readily apparent when we see Molly Solverson and her family in episode ten, Morton's Fork, watching television in identical postures and blankly staring at the television. This, and other such frozen moments, often last longer than would be necessary for narrative purposes and suggest an alternative pictorial approach being used in Fargo in the absence of a style that might be used to build the atmosphere of a classic noir adventure.

On the other hand, one of Hawley’s achievements as showrunner in Fargo has been to maintain an authoritative narrator that is reliable and objective because his 'grown-up stories require a long view... We have a responsibility to the audience to give them an experience that's fully thought out. ${ }^{\text {xxiv }}$ This links it to the challenge of 
representing an emotionally loaded series without it becoming a conventional serialised melodrama as might have been made for older network TV. If melodrama involves one overriding aesthetic goal - the invocation of 'vivid' emotions ${ }^{\mathrm{xxv}}$ - digression and suspense offer other assumptions about character and performance in Fargo. As we have seen with the murder of Nygaard's wife, noticeable performances within Fargo are often restrained, almost dignified: the opposite of vivid emotion. But if the emotional trauma of the death of Nygaard's wife using a hammer or the shooting of the Chief of Police in Nygaard's home excites little emotion, the show's general lack of stylistic excess calls attention to other textual pleasures in Fargo's unfolding storyworld.

As in the original film, each episode of the TV show begins with the text: 'This is a true story. The events depicted took place in Minnesota...At the request of the survivors, the names have been changed. Out of respect for the dead, the rest has been told exactly as it occurred.' In similar ways to the film, such a statement helps to explain the precision of some shots, which unlike the dialogue is not punctuated by gaps and pauses from characters such as Lester Nygaard and Gus Grimly. In his introduction to the film script of Fargo, Ethan Coen comments, '[Fargo] aims to be both homely and exotic, and pretends to be true.' ${ }^{x x v i}$ The need to recount the past - events that have happened and being told by a narrator - is as much a possible re-telling of actual events, as well as a memory of the original film. Seen like this, the assurance that the story is being told as it really happened suggests less a representation of the truth or abstraction of reality.

In fact, fidelity is important to the Coen brothers universe if not the film or supposed real-life events. The TV series does not use the characters of two hit men in the film played by Steve Buscemi and Peter Stormare. However, in the opening of episode one of Fargo, Billy Bob Thornton establishes the character of Lorne Malvo, the enigmatic drifter-assassin, who ignores the thump-thump from the boot of the car while his face is bathed in a red light. The eruption of sudden violence does not clearly instigate the show's narrative puzzle as may have happened in older dramas but, at least, initially, like the film finds a fascination with an entropic universe. After the thumpthump from the boot of the car, when a deer leaps across the highway, Malvo reveals a cold fascination with death as he crashes the car but ignores the man now escaping from the boot dressed only in boxer shorts. Instead, he gazes impassively at the dying deer he hit with the car, ignoring the man. Rather than the need to avoid television's 'commercial zapping' by involving the viewer in the narrative as soon as possible, 
Thornton's under-stated sensibility is more aligned to independent film. The use of style to de-emphasise the narrative is a risky choice but challenges assumptions about the pace of television drama, opening the possibility of a closer viewing of the shots.

\section{Tone and loss of textural determinism}

If the director's craft can be summed up as choosing pictorial compositions and handling actors within the frame of the image, the primary task of the director in television has for much of its history been to interpret the written story. However, recently, FX CEO John Landgraf argues that 'television has evolved from being more of a writer's medium to being a filmmakers’ medium as well...What passes for great television is just more visually ambitious... ${ }^{\text {xxvii }}$ Nevertheless, if it is too reductive to claim that television has been a writer's medium and film a director's medium, an often hierarchical system of job demarcation in television has historically separated the writer from the director and the production process. But, in the case of Fargo, it is possible to claim that, in important aspects, it is not possible to identify the production with a single author because television production is a collective enterprise often requiring elaborate teamwork for a complex production such as drama. Equally, as we have seen, Fargo relies on a pre-existing storyworld created by the Coen brothers before its adaptation to the mini-series.

As a further example of an operational aesthetic, Fargo involves tone or texture within the imagery, and these often reside in the locations for the production, as well as lighting and camerawork. Initially, the formal organisation in Fargo was established by both Hawley and director Adam Bernstein (Breaking Bad, House of Lies, Shameless). Bernstein was able to direct the first two episodes and with a credit as executive producer was able to be involved in production at an early stage. The similarities between the film and the TV series meant that for the first season the story would be set in Minnesota and be a small town noir crime thriller. The colour palette would also remain the same: in the film, beige, blue and red predominate and Bernstein ensured the TV series would maintain the colour palette. The tone is associated with the film but is also one that can be understood to be identified with the American Midwest - patriotic and homely, although possibly dull. Soft lighting is the key to the aesthetics in Fargo both indoors and outdoors, although this caused some problems maintaining sufficient detail in the shots which were important in the design of the show and the polished precision important to the poetics of the series. Bernstein's cinematographer was 
Matthew Lloyd, who shot the initial two episodes using the ARRI Alexa followed by Dana Gonzales for episodes three to ten. The Alexa is one of a new type of digital camera that has provided broadcasters with the opportunity to achieve a 'filmic' look and the qualities of $35 \mathrm{~mm}$ film. The colour palette of Fargo would be more easily captured for television due to the Alexa's ability for greater colour and contrast control. It is this control that allows for greater tonal control of the image and the possibility of a filmic image for television drama.

Once the aesthetic tone of the series had been established, the rotation of directors began. Episodes three and four were directed by Randall Einhorn; episodes five to six by Colin Bucksey; episodes seven and eight by Scott Winant; and episodes nine and ten by Matt Shakman. Continuity of style was made easier by the employment of John Cameron, an assistant director and/or producer on six Coen films, as coexecutive producer. ${ }^{\text {xxviii }}$ Cameron was also to work as a second unit director for Fargo. Continuity of style is a striking feature of each Fargo mini-series without allowing for the practice of allowing some of the series to deviate from the usual style as stand-alone episodes. Although season three of Fargo (2017) was to produce a stand-alone episode directed by Cameron set in Los Angeles, season one maintained a strict serial form. In this way, each episode felt part of a serial rather than a one hour film. If each episode could be a 'story of the week', offering further insight into the key characters it did not interrupt the key relationships between the ensemble cast.

In Fargo, unlike the interweaving and multiple storylines, the shots tend to be clear and neatly balanced. For Hawley the camera is detached: 'There's a dryness to the way the camera and music play against the scenes that is essential. ${ }^{\text {xxix }}$ As we have seen, by choosing to keep many events off-screen or else deploy a system of distant framing, events are presented using a camera style that keeps the spectator at a distance, although the narrative invites greater engagement. The complex use of tone and texture, at times, reduces the chaos of the narrative to manageable terms by often adopting a system of distant framing and use of off-screen space to suggest a restrained style. If storylines in many high-end dramas suggest 'contradictory truths' in a world that appears unknowable and unpredictable, the camera style in Fargo is the blank stare of the witness-observer. Moreover, in many scenes, the texture of the snow reduces the chaos suggested by the narrative and imposes stillness, inviting contemplative viewing. Such observational realism through the use of tonal control and detailed textures within the imagery can implicate the viewer less in the narrative action at key moments in the 
series. Yet, equally and perhaps conversely, such an approach also reveals more of the structures in Fargo by rewarding a close attention to visual style.

For example, although narrative structures remain important, the possibility of Televisuality without textual determinism is visible with the development of Nygaard, as well as with other characters. Stavros Milos played by Oliver Platt first appears in episode two, The Rooster's Prince. Milos is a local supermarket magnate, who is in his office at Phoenix Farms when he hires Malvo to find the writer of a blackmail letter sent to him. Milos is a typically Coenesque small-town autocrat, similar to figures such as Homer Stokes (O Brother, Where Art Thou) and Julian Marty (Blood Simple), who appear supremely confident in their own abilities to control a situation. Yet guilt presides at the core of Milos because he is haunted by the secret of how he found the money that permitted his rise as a successful businessman. The narrative is organised in a complex way, structured around flashback sequences of his finding the money. Yet, rather than the closed-in spaces of suspense drama dominated by shadows, stylistic texture permits subjective ways of experiencing the outdoors setting.

During the opening of episode four, Eating the Blame, the television series recalls the film when Milos has a flashback to his younger self. Milos discovers a suitcase of ransom money buried by the roadside, which ties up a loose end from the film - whatever happened to the suitcase buried by Carl Showalter? The homage to the film evokes a timeless quality as we watch Milos in his car travelling in the distance across the iconic snow covered mid-western backdrop. In the scene, Milos prays to God after he reaches rock bottom when his car runs out of gas with his family stuck in the middle of nowhere. But the episode not only responds emotionally through the edited narrative to Milos's misfortune - intercut with a sequence of his failing to stop a truck and falling to the ground - but also relies on the fluctuating meaning of the image. The sense of wonder initially evoked by the discovery of the suitcase results less in an interest about the money and questions about where it came from. In fact, the carefully positioned shot of the money in the suitcase is quickly forgotten as the scene becomes, in essence, a religious moment of affectation felt by Milos: as he explains, 'God is real'. Here, we have images existing in a dual mode; at once the narrated landscape, as well as more representative of a fragmented consciousness without clear resolution. The abandonment of a strongly directed 'authentic' account is tied to the prospect of a series of shots linked less to any form of clear agency. This strategy reoccurs at the end of the sixth episode, Buridan's Ass. The philosophic dilemma between two states of being is 
made manifest when Milos is again overwhelmed by a renewed state of religious emotion as he stands surrounded by a shower of fish fallen from the sky. Each 'moment of affect' presents an uneasy relation between the apparent absence of authorship and the need for textual evidence that explains the mysterious events. Without the possibility of fixed interpretation, the narrative fails to find resolution about Milos as the ambiguity of the fish falling from the sky deepens the mystery.

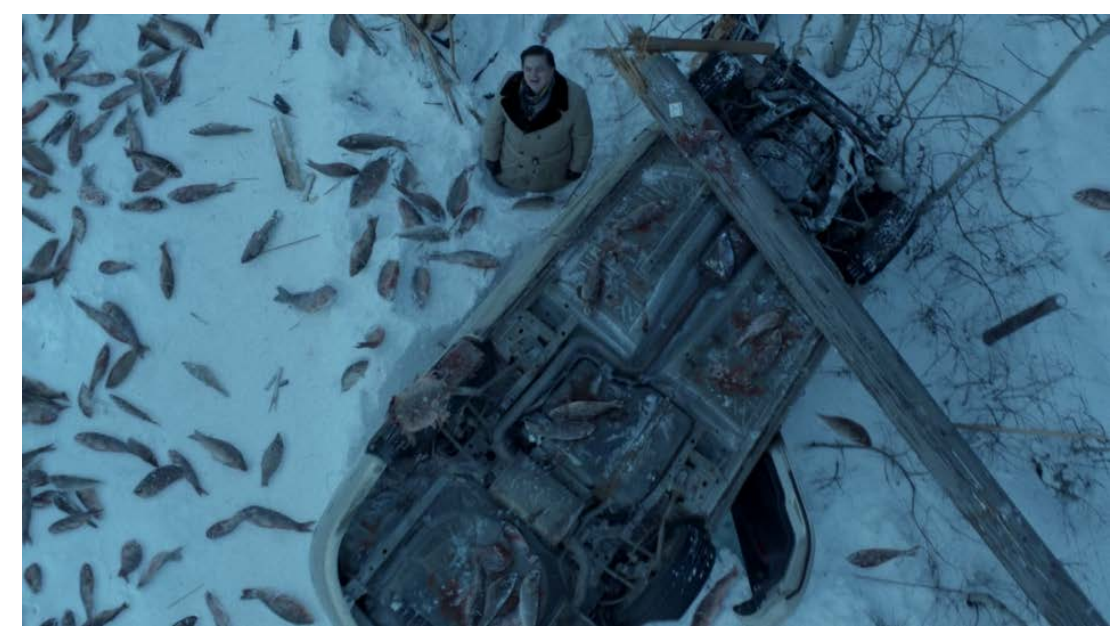

\section{Style and levels of narration}

By carefully alternating between levels of narration, Fargo marks, at key moments, a transition from an authored linear narrative that presents additional information to process. Instead, visual cues exist for spectators to identify other types of meanings, representations and effects. In this way, Fargo demonstrates a complex use of images that move it from the show's often fast-paced plot to shots that serve to not simply delay but diffuse interpretation. The achievement of Fargo is to make use of a regulated narrative form that, on the one hand, is open to structural analysis but, at the same time, seeks to present viewers with ontological questions about the nature and reliability of storytelling using complex imagery.

The importance of style can be seen again in Buridan's Ass when several narrative strands come to a head. Malvo is successfully blackmailing Milos, who agrees to make the ransom drop, believing that he is cursed by a series of Biblical plagues engineered by Malvo, including blood frothing from his shower. Yet the use of blood from the shower prefigures a refinement of the movement and texture of water that reoccurs throughout the episode, beginning with fish in a tank. As the visual imagery is developed in the episode, both effects and affects such as the intensity of the falling snow slowly engulfing the buildings produces ambiguities about the status of the shots. 
Layers of meaning are attached to various shots that a biblical-style tidal wave is about to swallow up its victims, as well as offering an unstable but converging relationship between several of the characters.

Buridan's Ass opens with a shot of fish in a tank of water.

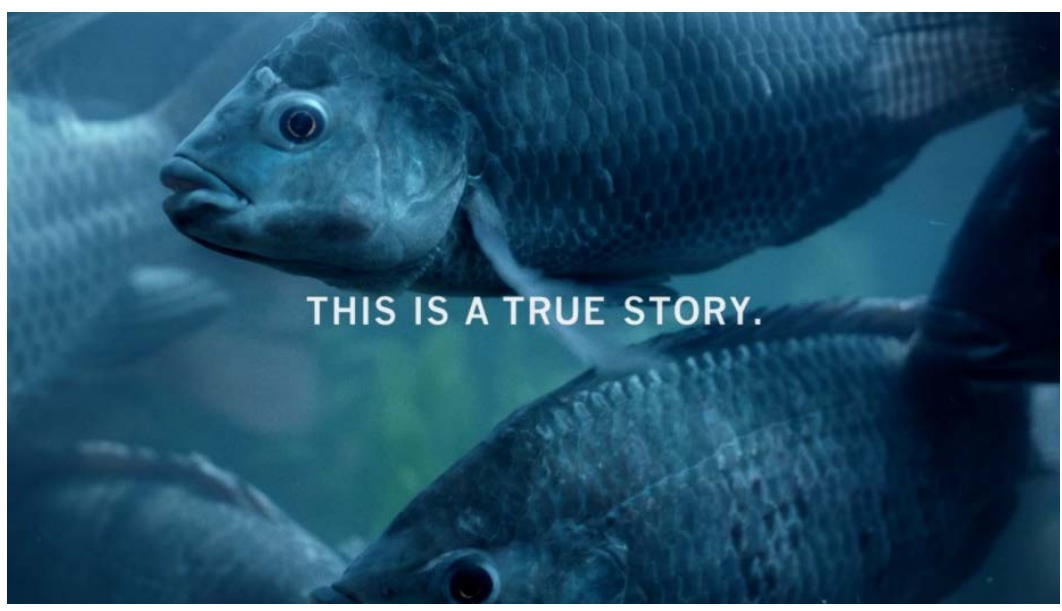

Later, this is followed by an aerial shot of snow swirling down as Milos's car drives up a multi-story carpark to make the drop of ransom money. To help create a sense of spinning vortex dragging everything into it, a subtle glow was added; another effect that re-emphasises texture. In this episode, as with others, light is a pointer to texture and in this scene and others we follow the movement of light that ties together several of the characters - Milos, Gimly, Solverson. In this way, multiple agencies are linked enabling a complex use of style that adds focus to other scenes in the episode.

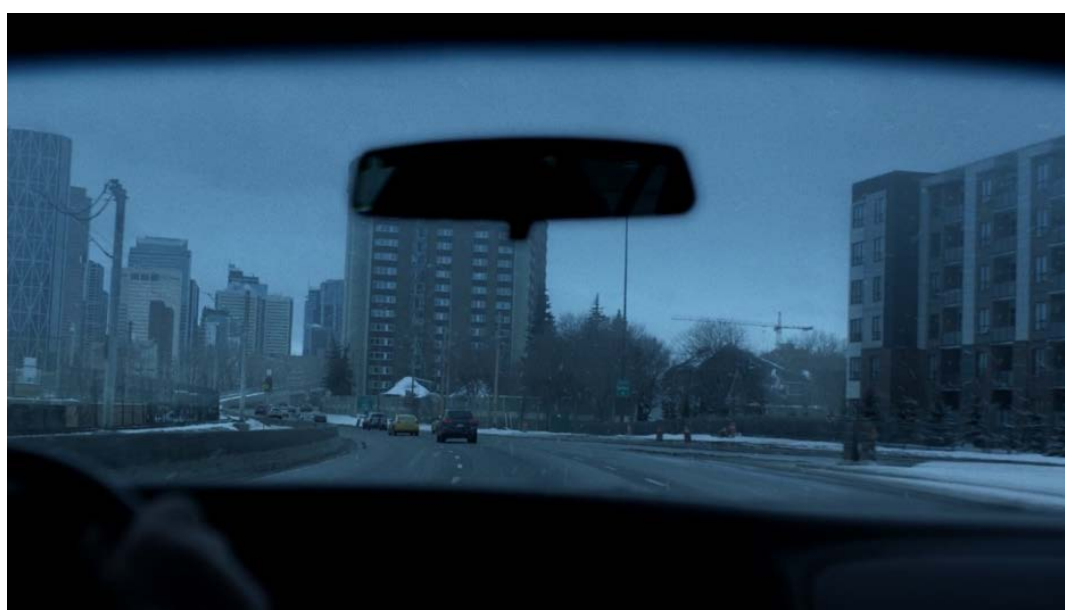

For example, initially, we are in a car driving to Bemidjo using a focalised shot from officer Grimly’s point of view. 


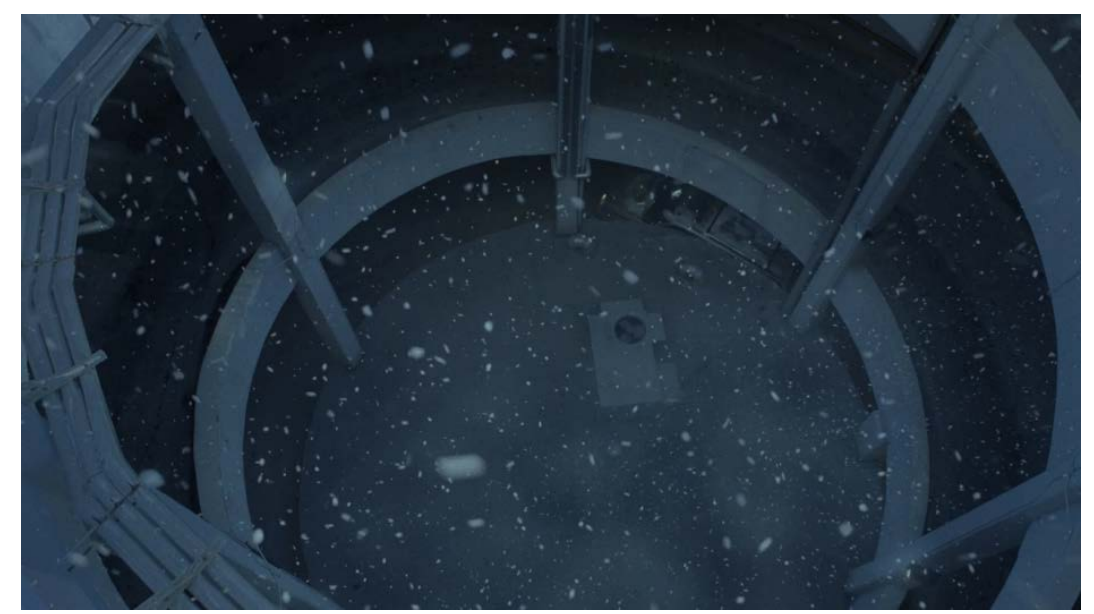

Next, the use of light and snow ties Grimly’s narration to Milos using a non-focalised shot as the snow becomes increasingly visible and the characters in the snowstorm appear to be confronted by the growing vortex, threatening to submerge them. Intercutting the scene in the carpark with the moment he discovered the money means that Milos appropriates the image: the flashback recounts his memory of the incident and his belief that God is real. This is important to establishing the sense of biblical climax. Formal elements such as light and colour continue to bring together Grimly, Milos, Solverson, and the killers - Mr Wrench and Mr Numbers - to create narrative uncertainty about whom or what anything is within the murk of the snowstorm.

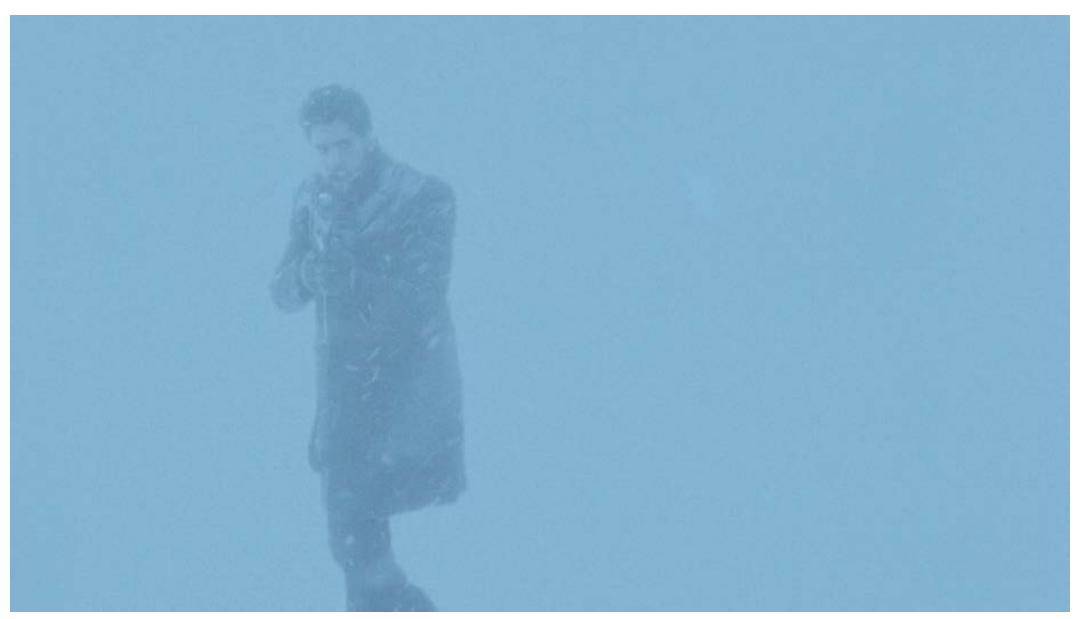

In these ways, the formal importance of small-scale, everyday detail in separate shots is intertwined in the thematic construction of a complex televisual story-world. Hawley talks about the TV series of Fargo being in a Coen brothers universe. ${ }^{\mathrm{xxx}}$ Although the television series is not an iteration of the film, its serial form much more than the film accumulates a wealth of detail about the characters that invites audiences to engage in themes borrowed from the film about existentialism and determinism that also permits a more complex style. If the television series is not about a crime series but a 
response to the crime of murder, its snow-filled milieu serves this aim. However, this can be not only through an analysis of the narrative that follows its various plot twists but, using visual techniques borrowed from the 'Coen brothers universe', it pushes formal possibilities by foregrounding a televisual aesthetic that no longer seeks to maximise narrative clarity.

\section{Vocal performance in Fargo}

If visual style is variegated, the accents delivered by the cast are also central to the fascination of the audience. For the TV series, the highly-experienced dialect coach, Tony Alcantar, was hired to closely train the cast in the regional accent. Accent is used as a device by the Coen brothers to disrupt the genre normality of the script, in particular around scenes of police procedural. Different strategies are at work in the TV series, and to interrogate these dissimilarities it is possible to closely analyse voice and performance in a sequence of twenty minutes into episode one, in which the police chief comes to investigate a crashed car beside the side of a snowy country road.

Television director Adam Bernstein uses elements of visual style to carefully link his scene with that from the movie. The location seems identical, the snowy prairie with its road and fence drawing a perspective line to emphasise the scale of the landscape; the freezing overcast weather conditions too are the same in both scenes. The staging and shooting of the scene repeatedly gives links to the movie. Even the reversal of gender provides emphasis of both the similarity and the difference between the two screen media: the police chief in the series is male, Vern Thurman (Shawn Doyle) and the colleague that he meets at the scene is female: Molly Solverson. Yet Bernstein positions Molly just as Ethan Coen had positioned Lou, waiting for the chief's patrol car to arrive on the empty road that stretches dead straight across the white landscape.

Brief dialogue exchanges between the colleagues about the cold weather also reflect the opening of the Coen brothers' scene; in both film and episode, the police officers are alone at the crime scene, allowing a personal as well as professional interaction. Chief Thurman moves through a scene analysis of the abandoned car just as Marge does in the feature film. However, cutting across this constant referencing of similarity between TV and movie is the uniformly different approach to vocal performance. It is difficult to adequately demonstrate a point of close aural analysis in the context of a written article, but when comparing the two scenes it is the accents of 
the actors that give the greatest divergence. McDormand and Bohne deliver their lines in lilting Minnesotan, with their accent and the Scandinavian gaps and hesitations 'hiccuping' the dialogue. Tolman and Doyle speak in a simple and clear accent, with only a hint of regional character; the dialogue flows smoothly and swiftly in a consistent and considered performance choice across the entire sequence. What Bernstein achieves in the sequence is a combination of unity with the original movie of Fargo, as well as distinctiveness. His choices of visual style take the audience into the unique Coen brothers world, while his direction of vocal performance establishes a very distinct televisual alternative.

The softer approach to the Minnesotan accent adds to the dual tone of the TV series and to the creation of its characters. Martin Freeman plays Lester Nygaard and his voice is key to Lester's professional persona: he is a salesman, his 'sales patter' is his livelihood. Freeman's vocal performance provides a lightness; an innocence to the character, reinforcing his status as a sensitive man within a thoughtlessly macho culture. But the TV show's decision to deploy a gentle quality of Minnesotan accent even extends to the bear of a man who confronts Lester in the street, the former school bully Sam Hess (Kevin O’Grady) who tormented Lester decades ago: this is not the deep, full throat voice of an American alpha male. The vocal delivery of O’Grady is relaxed despite his confrontational role in the scene; his use of the 'Minnesota accent' is as light as that of Martin Freeman. This delicacy of voice appears to be a deliberate performance choice. When we first hear a non-Minnesotan accent, in the hospital where Lester first meets the assassin Lorne Malvo (Billy Bob Thornton), the outsider's voice is gentle, almost soft in its questions to the protagonist. Thornton gives us a wolf-insheep's-clothing with his voice, while his eyes reveal the amoral assassin that lies beneath.

Similar to the visual style, the dominant feature of the vocal performances in Noah Hawley's Fargo is restraint. Although the show allows its audience to enjoy the otherness of the Minnesota culture, the soft approach to directing vocal performance is common across the three series. ${ }^{\mathrm{xxxi}}$

\section{Re-thinking complex modes of Televisuality}

This article examines how the use of images and performance in Fargo in episode one is an important prelude to creating complex character genealogies that relates the characters together in unexpected ways. This ability of style continues across episodes 
to de-stabilize the subjectivities of its main characters. The article concludes that any self-conscious imagery should be understood as a desire by the programme producers to make the show's interweaving storylines more complex.

It could be argued that the lighter-touch of the TV show compared to the film is linked to traditions of realism in the medium or else lies within theories of the 'glance' as the historic method of viewer engagement with television. However, as this article argues, by deploying restraint as part of its understated sensibility Fargo's visual sophistication becomes an invitation to reflect further on complex events in the text. We have seen how in various examples beginning with the character of Nygaard murdering his wife, an understated sensibility helps create an ordinariness that sits alongside the narrative's comedy and crime, allowing the audience to enjoy a more contemplative gaze.

If the television serial of Fargo is an example of forward plot momentum, its ludic capacities are a device that mark a rhetoric of distinction whose characters requires less a linear narrative or single biography. For example, the death of its various protagonists, who appear to have a central role until sudden death, plays on possibilities of an indefinite number of events. Narrative assumptions of the genre are also disrupted threatening the connection between protagonist and viewer as events unfold. At the same time, the complex visual and audio style in Fargo marks further shifts within the contemporary US mini-series that does not necessarily support the authored event-status show. First, if aesthetic unity exists in Fargo, this is not necessarily a personal style attributed to Noah Hawley, its showrunner. Rather, it demonstrates a complex and long production history between many different people that reflects industrial changes and the renegotiation of boundaries of formal strategies. Second, it raises questions about the function of style and how it draws attention to narrative elements or, as affective experiences, avoids interpretation of the character's states.

In these ways, any test of the possibility of poetics in Fargo, as well as other recent complex drama, demonstrates the requirement of a detailed analysis in addition to a general framework of paradigms about artistic excellence in contemporary high-end television US drama.

\footnotetext{
${ }^{\mathrm{i}}$ Joel Brinkley, Defining Vision: The Battle for the Future of Television, Harcourt Brace, 1998.

ii Caldwell, Televisuality, 73-102.
} 
iii Season 1 to 3 were produced 2014, 2015 and 2017 respectively. A fourth season is presently being filmed and due in 2019.

iv Robin Nelson, State of Play: Contemporary high-end TV drama, Manchester UP, 2007.

v Qtd in Christy Grosz, ‘Beyond Borders’, Emmy, 36:9, 2014, 57-59.

${ }^{\text {vi }}$ Budget figures for the shows are from Variety.

vii Janet McCabe and Kim Akass, Quality: contemporary American television and beyond, I. B. Tauris, 2007.

viii We are not suggesting here that richer implies that the text has greater aesthetic value. Rather, as this article wishes to demonstrate, we are suggesting that a series often deploys multiple forms that demand close attention.

ix Caldwell, Televisuality, 16.

x Catherine Shoard, 'Coen Brothers to adapt Fargo for TV channel FX', The Guardian, 5 August, 2013.

${ }^{x i}$ For more about the convergence between US serial drama and the made-for-television movie, see Todd Gitlin, Inside Prime Time, Pantheon, 1983, 66.

xii Distribution rights are handled by $21^{\text {st }}$ Century Fox

xiii A total of 85 days.

xiv Duchovny as Fox Mulder and Anderson as Dana Scully were to appear in 7 seasons. Mulder was more or less written out of the show after the seventh series to reappear in a few remaining episodes.

${ }^{x v}$ Accessed at: http://www.indiewire.com/2014/01/why-theres-no-marge-in-fxs-fargo-series-and-whatmade-billy-bob-thornton-believe-that-television-is-now-where-its-at-31228/

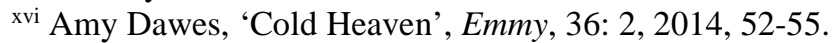

xvii Richard Levinson and William Link, Off-camera: conversations with the makes of prime-time television, New American Library, 1986, 142.

xviii Such industrial changes are beyond the scope of this article but more can be found in Robin Nelson, State of Play: contemporary high-end TV drama, Manchester UP.

xix See the interesting account of the problems encountered by $X$-Files when it was criticised for being overly-long. Simon Brown, 'Memento mori: The slow death of The X-Files', in Stacey Abbot, Science Fiction Film and Television, 6: 1 (Spring 2013). Themed issue: The X-Files 20 Years On, 7-22.

xx Stephen King, 'Stephen King issues a challenge to Lost execs', Entertainment Weekly, 1 February, 2007. Accessed at: http://ew.com/article/2007/02/01/stephen-king-issues-challenge-lost-execs/

${ }^{x x i}$ For more about the difference between beats and arcs, see Michael Newman, 'From Beats to Arcs:

Toward a Poetics of Television Narrative', Velvet Light Trap 58 (Fall 2006): 16-28.

xxii David Michael Wharton, 'Twin Brothers Alexi and Noah Hawley Are Dead in the Water', Creative Screenwriting, 13: 5, 12.

xxiii The idea of focalisation draws on Edward Branigan's theory of agents and levels of film analysis. See Edward Branigan, Narrative Comprehension and Film, Routledge, 1992.

xxiv Qtd in Liane Bonin Starr, 'Next Question', Emmy, 39: 5, 2017, 174-177.

${ }^{x x v}$ Daniel Gerould, 'Russian Formalist Theories of Melodrama', Journal of America Culture, 1: 1 (Spring 1978), 154.

${ }^{x x v i}$ Fargo (London: Faber and Faber, 1996)

xxvii Maureen Ryan and Cynthia Littleton, 'TV Series Budgets Hit the Breaking Point as Costs Skyrocket in Peak TV Era', Variety, 26 September, 2017. Accessed at: http://variety.com/2017/tv/news/tv-seriesbudgets-costs-rising-peak-tv-1202570158/

xxviii The films were Fargo, The Big Lebowski, O Brother, Where Art Thou, The Man Who Wasn't There, Intolerable Cruelty and The Ladykillers.

xxix Amy Dawes, 'Cold Heaven'.

xxx Debra Kaufman, 'Fargo on FX', Digital Video, May 2014, 22: 5, 15.

xxxi The achievement may be substantially due to the work of Tony Alcantar, who worked as dialect coach continuously throughout the three series, alongside thirteen different episode directors. 